\title{
The Fascinating Bird's Nest Mushroom, Secondary Metabolites and Biological Activities
}

\section{Waill A Elkhateeb ${ }^{*}$, Ghoson M Daba}

Chemistry of Natural and Microbial Products Department, Pharmaceutical Industries Division, National Research Centre, Dokki, Giza, 12622, Egypt.

\section{ARTICLE INFO:}

Received: 05 Feb 2021

Accepted: 16 Feb 2021

Published: 28 Feb 2021

Corresponding author * Waill A Elkhateeb,

Chemistry of Natural and Microbial Products Department,

Pharmaceutical Industries

Division, National Research

Centre, Dokki, Giza, 12622 ,

Egypt.

E Mail: waillahmed@yahoo.com

\begin{abstract}
:
Background: Mushrooms are generous source of nutritional and medicinal compounds. Bird's nest fungi are a gasteromyceteous group of mushrooms named for their similarity in shape to small bird's nests. They are considered from the tiniest and most interesting mushrooms all over the world. It is usually found in shady moist environments, and typically survive on plant debris, soil, decaying wood, or animal's excrement. Bird's nest mushrooms are inedible, though they were not previously reported to be poisonous, due to their tiny size. Object: this review aims to put bird's nest mushrooms under light spot through describing their morphology and ecology especially of the most common fungus, Cyathus haller. Moreover, discussing important secondary metabolites and biological activities exerted by bird's nest mushrooms.

Conclusion: bird's nest mushrooms are able to produce many novel and potent secondary metabolites that exerted different bioactivities especially as antimicrobial, antitumor, and anti-neuro inflammation activities. Further studies and investigations are encouraged in order to find more about this interesting tiny mushroom.
\end{abstract}

Keywords: Bird's nest fungi, Cyathus spp., secondary metabolites, biological activities.

\section{INTRODUCTION}

Mushrooms are abundant natural resources that have structurally unique compounds with diverse bioactivities [14].Mushrooms are generally basidiomycetous fungi except for some species. Mushrooms have been reported to be from the most valuable microbes to humankind $[5,6]$. Investigations on the therapeutic and nutritional properties of mushrooms are ongoing throughout the world. Researchers are providing vital data on the collection of biologically active secondary metabolites originated from mushrooms. Generally, mushrooms grow wild in many environments around the world and are also commercially cultivated for pharmaceutical and nutritional purposes. Nutritionally, mushrooms are healthy food which is rich in nutrients and vitamins. On the other hand, mushrooms have pharmaceutical and medical applications from centuries especially in Asian countries [7-9].

Recently, isolation and purification of biologically active secondary metabolites from mushrooms has been conducted mainly on the products of fruiting bodies. However, collection of fruiting bodies is a difficult work and is limited by collecting season and area. Also the small amounts of the collected samples are limited to find metabolites from mushrooms. Thus, mycelial culture of basidiomycetes and ascomycetes originated from wild mushrooms would be suggested as an alternative, dependable, and controllable method that can obtain various bioactive metabolites from mushrooms [10-14].

The genus Cyathus Haller ecology and description

Bird's nest fungi are a group of mushrooms named for their similarity to small bird's nests. These fungi can be found worldwide. Bird's nest fungi are saprophytes (microorganisms that live on dead organic matter) [15]. In temperate areas, where conditions are damp and shady, bird's nest fungi can be found anytime of the year. However, autumn is the season in which they are most commonly seen. These tiny fungi are usually identified by the formation of a brownish, greyish, or sometimes whitish outer "nest", carrying brown or white eggs like structures inside it. These eggs like structures are the peridioles which are actually spore-containing structures that act as protective sacs for the mushroom's spores, and are located within the cup-shaped nest-like fruiting body. 
International Journal of Pharma Research and Health Sciences, 2021; 9 (1): 3265-3269

Bird's nest fungi are gasteromyceteous fungi, and the most common genera of bird's nest fungi are Crucibulum spp., Cyathus spp., Mycocalia spp., Nidularia spp., and Nidula spp. These fungi are often found in shaded, moist environments, and typically survive on plant debris, soil, decaying wood, or animals (cows and horses) excrement [15-19].

The characteristic cup and eggs structure (reproductive structure) of the bird's nest fungi is almost metallic looking, like shiny river stones. It provides a unique spores dispersing mechanism. In a storm, the "eggs" are splashed out of the "cups" by raindrops. "Eggs" can travel for a distance as long as about one meter or more before sticking to another object. When the "egg" became dry, it releases fungal spores. When the spores germinate, they grow into branching filaments called hyphae. The mass of hyphae (called mycelium) weaves through moist woody debris and consumes the wood to fuel its growth [16-21].

The genus Cyathus Haller (belongs to Division: Basidiomycota; Class: Basidiomycetes; order Nidulariales; Family; Nidulariaceae ) can be characterized by its peridium vase-like or infundibuliform to inverted bell-shaped with 3 layers, surface plicate or smooth, often covered with shaggy or tomentose hairs on the outside; peridiole (gleba) lensshaped and attached to the peridium with a thread-like cord (funiculus); basidiospores hyaline, smooth and mostly with a thick wall, while the shape and size vary [20-23]. In other similar genera like Nidulaspp., andCrucibulum spp., Nidularia spp., and Mycocalia spp. Nidula funicular cord with the peridiole is absent which is different than Cyathus. Moreover, Crucibulum has a single-layered peridium and white to yellowish peridioles, while peridioles appear black to dark brown in Cyathus [24-26]. Cyathus is the genus with the most species of bird's nest fungi and is represented by 45 species worldwide [27], 14 of which are from India [25-28]. Because bird's nest fungi are harmless to surrounding living plants, animals, or humans, no need to control growth of these mushrooms. Bird's nest fungi are inedible, though they were not previously reported to be poisonous, due to their tiny size. Bird's nest fungi have natural composting abilities and as aforementioned, it isn't harmful to humans, animals or living plants (Figure, 1).

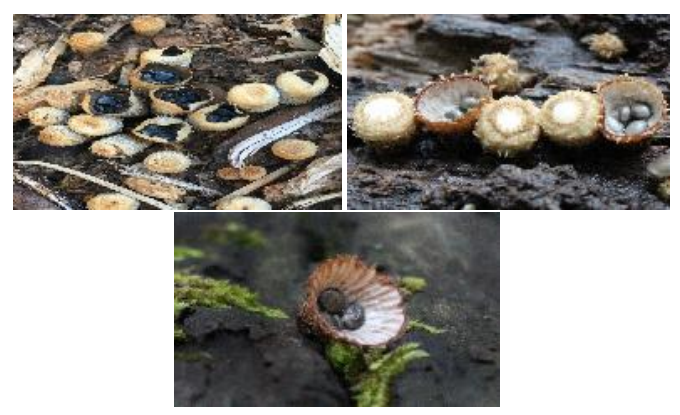

Fig 1: Different Cyathusspp. (Bird's nest fungi), Collected by Christine Braaten Locality: United States, Tennessee, Vonore, Kahite.Hosted by http://mycoportal.org).

\section{BIRD'S NEST FUNGIAS SOURCE OF BIOLOGICALLY ACTIVE COMPOUNDS}

Screening of fungi for antimicrobial substances, antitumor substances and others in particular has been greatly enhanced. Ascomycetes and Basidiomycetes mushrooms are known to produce wide range of secondary metabolites. Many interesting compounds were isolated and purified from different species of the basidiomycetous genus, Cyathus such as cyathane diterpenoids with unusual 5/6/7 tricyclic skeleton, including their xylosides [29].

The anti-inflammatory, antimicrobial and antitumor compounds isolated from these mushrooms belong to different chemical classes includingsteroids, terpenes, polysaccharides, fatty acids, phenolic acids, and other metabolites. Taofiq et al., [31], reported that terpenoids, phenolic compounds, and polysaccharides were the most potent compounds causing the anti-inflammatory action exerted by some mushrooms as described in different studies. Diterpenes have been proven to display a wide range of biological properties, including anti-inflammatory [31, 32], antimicrobial [33] antitumor [34]. Previous chemical studies on Cyathus striatus resulted in the discovery of antitumor cyathane-type metabolites such as the striatals A, B, C, and D [33, 34].

Liu and Zhang, [35], studied twelve different Cyathus species for their capabilities to produce antimicrobial secondary exo-metabolites. These exo-metabolites were able to inhibit some human pathogenic fungi and yeast such as Aspergillus fumigatus, Cryptococcus neoformans, and Candida albicans. The antimicrobial activities of those twelve Cyathus species extracts against human pathogenic bacteria were also reported. In another study, the antimicrobial compounds striatins A, B, C were isolated from Cyathus striatus during mycelial growth. Striatins A, $\mathrm{B}, \mathrm{C}$ were highly potent when tested against different Gram positive and negative bacteria, as well as against some fungi imperfecti [36].

Kang et al., [3], reported that three new polyketides, cyathuscavins A, B, and C were isolated from the mycelium culture of Cyathus stercoreus, and the structures of the three compounds were explained by NMR and mass spectroscopic data. Antioxidant activities of the three compounds were evaluated by the scavenging ability against ABTS+, DPPH, and superoxide anion radicals, and resulted that Cyathuscavins A-C showed significant antioxidant activity similar to those of reference antioxidants, BHA and Trolox. Neurodegenerative diseases, such as Alzheimer's disease and Parkinson's disease, affect millions of people worldwide [37]. Neurodegenerative diseases are happening when cells in the brain or peripheral nervous system dysfunction by time and eventually die [38, 39]. Neurotrophins promote the survival, maintenance, and regeneration of neuronal populations and can be used as a remedy against neurodegenerative diseases. Many researches in recent years, 
International Journal of Pharma Research and Health Sciences, 2021; 9 (1): 3265-3269

have been focusing on natural products with the potential for treating neurodegenerative disorders [40, 41].

It is vital to search and explore novel bioactive natural products to alleviate neurodegenerative disorders. Cyathus species are well known as producers of bioactive cyathane diterpenoids. Ten novel cyathane diterpenoids out of 14 were isolated from the medicinal mushroom Cyathus africanus which was cultivated on broth medium [42]. Cyathane diterpenoids from Cyathus spp. showed great potentials on both neurotrophic activities and antineuroinflammation activities [43-46]. Yin et al., [47], reported that three novel cyathane diterpenoids stercorins A$\mathrm{C}$ and two new drimane sesquiterpenoids stercorins D and $\mathrm{E}$ were isolated from Cyathus stercoreus. Stercorins A-C displayed promising neurotrophic activity in PC-12 cells and significantly suppressed LPS induced NO production in BV2 cells. Kou et al., [46], reported that, five terpenoids, including two new cyathane diterpenoids neocyathin $S$ and neocyathin $\mathrm{T}$, together with three drimane sesquiterpenoids, one known 3 $3,6 \beta$-dihydroxycinnamolide, two new ones $3 \beta$ ,6 $\alpha$-dihydroxycinnamolide and2-keto-3 $3 \beta \quad 6 \quad \beta \quad$ dihydroxycinnamolide, were isolated from the cultures of the basidiomycete Cyathus africanus. All the five compounds enhanced nerve growth factor (NGF)-mediated neurite outgrowth using rat pheochromocytoma (PC12) cells at concentration $10 \mu \mathrm{M}$.

By Chemical investigation eleven new cyathane diterpenoids, designated as cyafricanins A-K, were isolated by Yin et al., [33], from the culture broth of the basidiomycetous Cyathus africanus (Common name is bird's nest fungi). Their structures were explained by NMR and HRESIMS data. All compounds were investigated for their neurotrophic effect in PC-12 cells as well as their antineuroinflammatory activity in BV2 microglia cells. All of the tested diterpenoids exhibited nerve growth factor induced neurite outgrowth-promoting activity. Cyafricanin A, exhibit anti-neuroinflammatory activity via the inhibition of pro-inflammatory enzymes expression. Also among all of them, cyafricanin B and cyafricanin $G$ were the most potent neurotrophic activity.Cyathus africanus produced different range of cyathanes diterpenoids depending on the fermentation conditions and the period of the fermentation [48-50].

The novel polyoxygenated cyathane diterpenoids (neocyathin A-J), together with four known diterpenes, were also isolated from Cyathus africanus cultivated on broth medium. Those compounds were evaluated for their potential anti-neuroinflammatory activities in BV2 microglia cells. Several compounds showed differential effects on the expression of inducible nitric oxide synthase (iNOS) and cyclooxygenase-2 in lipopolysaccharide stimulated and A $\beta 1-42$ treated mouse microglia cell line BV-2. Molecular docking revealed that these bioactive compounds could interact with iNOS protein other than COX-2 protein. All isolated 14 cyathane diterpenoids together, might serve as important lead compounds for drug discovery against neuroinflammation specially including in Alzheimer's disease [51-55].

\section{CONCLUSION}

Bird's nest fungi are inedible, gasteromyceteous mushrooms which are capable of secreting many new and promising secondary metabolites. These metabolites showed variable bioactivities including antimicrobial, antitumor, and antineuro inflammation. Information about this mushroom are still unclear. Understanding the unexplored characteristics and potentials of this tiny and fascinating mushroom is highly challenging. Moreover, further investigations, especially those describing in vivo studies are required in order to find out more about this interesting tiny mushroom.

\section{REFERENCES}

1. Wasser SP, Weis AL. Medicinal properties of substances occurring in higher basidiomycetes mushrooms: current perspectives. Int J Med Mushrooms 1999; 1: 1-10.

2. Kang HS, Jun EM, Park SH, Heo SJ, Lee TS, Yoo ID, et al. Cyathusals A, B, and C, antioxidants from the fermented mushroom Cyathus stercoreus. J Nat Prod 2007; 70, 1043-5.

3. Kang HS, Kim KR, Jun EM, Park SH, Lee TS, Suh JW, et al. Cyathuscavins $\mathrm{A}, \mathrm{B}$, and $\mathrm{C}$, new free radical scavengers with DNA protection activity from the Basidiomycete Cyathus stercoreus. Bioorganic Med Chem Lett 2008; 18: 4047-50.

4. Elkhateeb WA, Daba GM, Thomas, PW, Wen TC. Medicinal mushrooms as a new source of natural therapeutic bioactive compounds. Egypt Pharmaceut J 2019; 18: 88-101.

5. Robles-Hernández L, González-Franco AC, Soto-Parra JM, Montes-Domínguez FE. Review of agricultural and medicinal applications of basidiomycete mushrooms. Tecnociencia Chihuahua 2008; 2: 95-107.

6. El-Hagrassi A, Daba G, Elkhateeb WA, Ahmed, E, Negm El-Dein A, Fayad W, et al. In vitro bioactive potential and chemical analysis of the n-hexane extract of the medicinal mushroom, Cordyceps militaris. Malays J Microbiol 2020; 16: 40-8.

7. Rahi DK, Rajak RC, Shukla KK, Pandey AK. Diversity and nutraceutical potential of wild edible mushrooms of Central India. Microbial Diversity: Current Perspectives and Potential Applications 2005; 967-80.

8. Wasser S. Medicinal mushroom science: Current perspectives, advances, evidences, and challenges. Biomed J 2014; 37: 1-10.

9. Rahi DK, Malik D. Diversity of mushrooms and their metabolites of nutraceutical and therapeutic significance. J Mycol 2016; 1-10.

10. Lin SY, Chen YK, Yu HT, Barseghyan GS, Asatiani $\mathrm{MD}$, Wasser SP, et al. Comparative study of contents of 
International Journal of Pharma Research and Health Sciences, 2021; 9 (1): 3265-3269

several bioactive components in fruiting bodies and mycelia of culinary-medicinal mushrooms. Int $\mathrm{J}$ Med Mushrooms 2013; 15: 1-10.

11. Elkhateeb WA, Daba GM, Elnahas M, Thomas P, Emam M. Metabolic profile and skin-related bioactivities of Cerioporus squamosus hydromethanolic extract. Biodiversitas Journal of Biological Diversity 2020; 21(10).

12. Elkhateeb WA, Daba G. The endless nutritional and pharmaceutical benefits of the Himalayan gold, Cordyceps; Current knowledge and prospective potentials. Biofarmasi Journal of Natural Product Biochemistry 2020; 18: 70-7.

13. Elkhateeb WA, Daba GM. Termitomyces Marvel Medicinal Mushroom Having a Unique Life Cycle. Open Access Journal of Pharmaceutical Research 2020; 4: $1-4$.

14. Daba GM, Elkhateeb W, ELDien AN, Fadl E, Elhagrasi A, Fayad W, et al. Therapeutic potentials of n-hexane extracts of the three medicinal mushrooms regarding their anti-colon cancer, antioxidant, and hypocholesterolemic capabilities. Biodiversitas Journal of Biological Diversity 2020; 21: 1-10.

15. Elkhateeb WA. What medicinal mushroom can do?. Chem Res J 2020, 5: 106-118.

16. Barbosa MM, Cruz RH, Calonge FD, Baseia IG. Two new records of Cyathus species for South America. Mycosp 2014; 5: 425-8.

17. Gehrig I, Bart HJ, Anke T, Germerdonk R. Influence of morphology and rheology on the production characteristics of the basidiomycete Cyathus striatus. Biotechnol Bioeng 1998; 59: 525-33.

18. Zhao R, Desjardin D, Soytong K, Hyde K. A new species of bird's nest fungi: characterisation of Cyathus subglobisporus sp. nov. based on morphological and molecular data. Persoonia: Molecular Phylogeny and Evolution of Fungi 2008; 21: 71.

19. Martin MP, Cruz RH, Duenas M, Baseia IG, Telleria MT. Cyathus lignilantanae sp. nov., a new species of bird's nest fungi (Basidiomycota) from Cape Verde Archipelago. Phytotaxa 2015; 236: 161-72.

20. Accioly T, Cruz RH, Assis NM, Ishikawa NK, Hosaka $\mathrm{K}$, Martín MP, et al. Amazonian bird's nest fungi (Basidiomycota): Current knowledge and novelties on Cyathus species. Mycoscience 2018; 59: 331-42.

21. Zhou TX, Zhao LZ, Zhao RL, Chen YH. Bird's nest fungi from China. Fungal Divers 2004; 17: 243-51.

22. Matheny PB, Curtis JM, Hofstetter V, Aime MC, Moncalvo JM, Ge ZW, et al. Major clades of Agaricales: a multilocus phylogenetic overview. Mycologia 2006; 98: 982-95.

23. Miller OK Jr, Miller HH. Gasteromycetes: Morphological and Development Features with Keys to the Orders, Families, and Genera. Eureka, CA, USA: Mad River Press, 1988.
24. Kanad DA, Hembrom ME, Parihar A, Zhao RL. A new species of Cyathus (Agaricaceae) from India. Turk J Botany 2015; 40: 97-103.

25. Zhao R, Jeewon R, Desjardin DE, Soytong K, Hyde KD. Ribosomal DNA phylogenies of Cyathus: is the current infrageneric classification appropriate? Mycologia 2007; 99: 385-95.

26. Das K, Zhao R. Bird's nest fungi in India: a new record from Sikkim. In: Biju KA, Nayar MP, Varma RV, Peethambaran CK, editors. Biodiversity and taxonomy, New Delhi, India: Narendra Publishing House, 2012, 61-68.

27. Das K, Zhao R. Nidula shingbaensis sp. nov., a new bird's nest fungus from India. Mycotaxon 2013; 125: 53-8.

28. Kirk PM, Cannon PF, Minter DW, Stalpers JA. Dictionary of the Fungi, 10th Ed., CABI, UK.2008.

29. Thind IP. Distribution of gasteromyceteous fungi in north western Himalayas. In: Dargan JS, Atri NS, Dhingra GS, editors. Fungi Diversity and Conservation in India, Dehradun, India: Bishen Singh Mahendra Pal Singh, 2005; 183-91.

30. Nakada M. Enantio selective total syntheses of cyathane diterpenoids. Chem Rec 2014; 14: 641-62.

31. Taofiq O, Martins A, Barreiro MF, Ferreira IC. Antiinflammatory potential of mushroom extracts and isolated metabolites. Trends Food Sci Technol 2016; 50: 193-210.

32. Kamo $T$, Imura $Y$, Hagio $T$, Makabe $H$, Shibata $H$, Hirota M. Anti-inflammatory cyathane diterpenoids from Sarcodon scabrosus. Biosci Biotechnol Biochem 2004; 68: 1362-5.

33. Yin X, Wei J, Wang WW, Gao YQ, Stadler M, Kou RW, et al. New cyathane diterpenoids with neurotrophic and anti-neuroinflammatory activity from the bird's nest fungus Cyathus africanus. Fitoterapia 2019; 134: 201-9.

34. Bai R, Zhang CC, Yin X, Wei J, Gao JM. Striatoids A$\mathrm{F}$, cyathane diterpenoids with neurotrophic activity from cultures of the fungus Cyathus striatus. J Nat Prod 2015; 78: 783-8.

35. Liu YJ, Zhang KQ. Antimicrobial activities of selected Cyathus species. Mycopathologia 2004; 157: 185-9.

36. Shittu OB, Alofe FV, Onawunmi GO, Ogundaini AO, Tiwalade TA. Mycelial growth and antibacterial metabolite production by wild mushrooms. Afr J Biomed Res 2005; 8: 157-62.

37. Allen SJ, Watson JJ, Shoemark DK, Barua NU, Patel NK. GDNF, NGF and BDNF as therapeutic options for neurodegeneration. Pharmacol Ther 2013, 138: 155-75.

38. Lin CW, Wu MJ, Liu IY, Su JD, Yen JH. Neurotrophic and cytoprotective action of luteolin in PC12 cells through ERK-dependent induction of Nrf2-driven HO-1 expression. J Agric Food Chem 2010; 58: 4477-86.

39. Menzies FM, Fleming A, Caricasole A, Bento C, Andrews SP, Ashkenazi A. ubinsztein DC. Autophagy 
International Journal of Pharma Research and Health Sciences, 2021; 9 (1): 3265-3269

and neurodegeneration: pathogenic mechanisms and therapeutic opportunities. Neuron 2017; 93: 1015-34.

40. Waters SP, Tian Y, Li YM, Danishefsky SJ. Total synthesis of (-)-scabronine $\mathrm{G}$, an inducer of neurotrophic factor production. J Am Chem Soc 2005; 127: 13514-5.

41. Tang D, Xu YZ, Wang WW, Yang Z, Liu B, Stadler M, et al. Cyathane diterpenes from cultures of the bird's nest fungus Cyathus hookeri and their neurotrophic and anti-neuroinflammatory activities. J Nat Prod 2019; 82: 1599-608.

42. Wei J, Guo WH, Cao CY, Kou RW, Xu YZ, Górecki M, et al. Polyoxygenated cyathane diterpenoids from the mushroom Cyathus africanus, and their neurotrophic and anti-neuroinflammatory activities. Sci Rep 2018; 8: $1-15$.

43. Tang HY, Yin X, Zhang CC, Jia Q, Gao JM. Structure diversity, synthesis, and biological activity of cyathane diterpenoids in higher fungi. Curr Med Chem 2015; 22: 2375-91.

44. Richter C, Helaly SE, Thongbai B, Hyde KD, Stadler M. Pyristriatins A and B: pyridino-cyathane antibiotics from the basidiomycete Cyathus cf. striatus. J Nat Prod 2016; 79: 1684-8.

45. Cao CY, Zhang CC, Shi XW, Li D, Cao W, Yin X, et al. Sarcodonin $\mathrm{G}$ derivatives exhibit distinctive effects on neurite outgrowth by modulating NGF signaling in PC12 cells. ACS Chem Neurosci 2018; 9: 1607-15.

46. Kou RW, Du ST, Li YX, Yan XT, Zhang Q, Cao CY, et al. Cyathane diterpenoids and drimane sesquiterpenoids with neurotrophic activity from cultures of the fungus Cyathus africanus. J Antibiot 2019; 72:15-21.

47. Yin X, Qi J, Li Y, Bao ZA, Du P, Kou R, et al. Terpenoids with neurotrophic and antineuroinflammatory activities from the cultures of the fungus Cyathus stercoreus. Nat Prod Res 2020, 1-10.

48. Han J, Chen Y, Bao L, Yang X, Liu D, Li S, et al. Antiinflammatory and cytotoxic cyathane diterpenoids from the medicinal fungus Cyathus africanus. Fitoterapia 2013; 84: 22-31.

49. Xu Z, Yan S, Bi K, Han J, Chen Y, Wu Z, et al. Isolation and identification of a new anti-inflammatory cyathane diterpenoids from the medicinal fungus Cyathus hookeri Berk. Fitoterapia 2013; 86: 159-62.

50. Enquist JA, Stoltz BM. Synthetic efforts toward cyathane diterpenoid natural products. Nat Prod Res 2009; 26: 661-80.

51. Wei J, Cheng Y, Guo WH, Wang DC, Zhang Q, Li D, et al. Molecular diversity and potential antineuroinflammatory activities of cyathane diterpenoids from the Basidiomycete Cyathus africanus. Sci Rep 2017; 7: 1-14.

52. Öztürk M, Tel-Çayan G, Muhammad A, Terzioğlu P, Duru ME. Mushrooms: a source of exciting bioactive compounds. In Studies in Natural Products Chemistry 2015; 45: 363-456.

53. Kushairi N, Tarmizi NA, Phan CW, Macreadie I, Sabaratnam V, Naidu M, et al. Modulation of neuroinflammatory pathways by medicinal mushrooms, with particular relevance to Alzheimer's disease. Trends Food Sci Technol 2020; 104: 153-62.

54. Phan CW, David P, Naidu M, Wong KH, Sabaratnam V. Therapeutic potential of culinary-medicinal mushrooms for the management of neurodegenerative diseases: diversity, metabolite, and mechanism. Crit Rev Biotechnol 2015; 35: 355-68.

55. De Silva DD, Rapior S, Sudarman E, Stadler M, Xu J, Alias SA, et al. Bioactive metabolites from macrofungi: ethnopharmacology, biological activities and chemistry. Fungal Divers 2013; 62: 1-40.

CONFLICT OF INTEREST: The authors declare no conflict of interest, financial or otherwise.

SOURCE OF FUNDING: None.

AVAILABILITY OF DATA AND MATERIALS: Not applicable.

CONSENT FOR PUBLICATION: Not applicable. ETHICS APPROVAL AND CONSENT TO
PARTICIPATE: Not applicable.

HUMAN AND ANIMAL RIGHTS: No animals/humans were used for this study. 